Introduction

\title{
Foreword by the Chairman of the EISCAT Council
}

The 9th International EISCAT Workshop in Werningerode marked a clear turning point of the EISCAT Scientific Association, since it was the first occasion for our community to present and discuss data from the EISCAT Svalbard Radar. The new and rich opportunities in space and plasma physics were immediately obvious. The very high latitude ionosphere and magnetosphere prove to be even more dynamic and very different from the auroral latitudes; much more than we had expected. We will need all the new capabilities of the ESR facility, including future upgrades, to fully exploit the excellent science possibilities which are now in our hands. This Special Issue of Annales Geophysicae is the first Journal to highlight the initial results, and I believe that it heralds significant scientific progress in our field. I expect to see many advancements over the years to come using the entire set of EISCAT facilities. Another point of great pleasure for me at the Werningerode Workshop and in this Special Issue is to see that a shift in the generation of the Association is taking place. A very large attendance of young scientists, in particular from our new associate country Japan, bear witness to the attractiveness of high latitude incoherent scatter research. With excellent new facilities, forming the first network of incoherent scatter radars, and a new generation of young scientist utilising the data, we can look forward to a productive and prosperous future of the EISCAT Scientific Association.

Uppsala, August 2000

Hermann J. Opgenoorth 